\title{
Leaf Water Status and Its Relationship with Reproductive Responses of Common Bean (Phaseolus vulgaris L.) Genotypes under Water Stress
}

\author{
Apurba Kanti Choudhury ${ }^{1 *}$, Md Abdul Karim², Md Moynul Haque², Qazi Abdul Khaliq², \\ Jalal Uddin Ahmed ${ }^{3}$, Mohammad Mofazzal Hossain ${ }^{4}$ \\ ${ }^{1}$ On-Farm Research Division, Bangladesh Agricultural Research Institute, Joydebpur, Bangladesh \\ ${ }^{2}$ Department of Agronomy, Bangabandhu Sheikh Mujibur Rahman Agricultural University, Gazipur, \\ Bangladesh \\ ${ }^{3}$ Department of Crop Botany, Bangabandhu Sheikh Mujibur Rahman Agricultural University, Gazipur, \\ Bangladesh \\ ${ }^{4}$ Department of Horticulture, Bangabandhu Sheikh Mujibur Rahman Agricultural University, Gazipur, \\ Bangladesh \\ Email: *bd apurba@yahoo.com, akarim1506@yahoo.com, moynul60@yahoo.com, khaliq53@yahoo.com, \\ jahmed06@gmail.com, mdmofazzal.bsmrau@gmail.com
}

Received 16 March 2014; revised 15 April 2014; accepted 27 April 2014

Copyright (C) 2014 by authors and Scientific Research Publishing Inc.

This work is licensed under the Creative Commons Attribution International License (CC BY). http://creativecommons.org/licenses/by/4.0/

c) (i) Open Access

\section{Abstract}

Two tolerant (BB24 and BB43) and two susceptible (BARI busbean-2 and BB04) genotypes of common bean (Phaseolus vulgaris $\mathrm{L}$.) were evaluated for their water status and its relationship with reproductive responses under continuous water stress $(50 \%$ field capacity) and control $(80 \%$ field capacity) conditions in a net house covered with polyethylene sheet at the Bangabandhu Sheikh Mujibur Rahman Agricultural University, Bangladesh. Under water stress condition, the susceptible genotype namely BB04 exhibited more negative leaf water potential (LWP) which was followed by that of BARI bushbean-2 in all the time of the day except at noon. The tolerant genotype namely BB24 exhibited less negative LWP at noon. The tolerant genotypes maintained higher relative water content (WRC) than the susceptible ones from dawn to dusk. The relationship between RWC and LWP was examined separately for four genotypes under water stress condition. The genotype BB24 showed a smaller decrease in RWC with more negative LWP than BB04. Water stress reduced pod setting ratio. The relationship between the leaf water status and reproductive responses showed that the genotype with a little reduction in mid-day drop of RWC or with high

*Corresponding author.

How to cite this paper: Choudhury, A.K., et al. (2014) Leaf Water Status and Its Relationship with Reproductive Responses of Common Bean (Phaseolus vulgaris L.) Genotypes under Water Stress. American Journal of Plant Sciences, 5, $1547-1556$. 
mid-day RWC displayed a high pod setting ratio.

Keywords

Leaf Water Potential, Pod Setting Ratio, Relative Water Content

\section{Introduction}

Common bean (Phaseolus vulgaris L.) is an important grain legume widely cultivated in Central and Southern America. It contributes to $90 \%$ of the total world bean production [1]. In Bangladesh, this crop is known as "Farashi Sheem" and is cultivated in a limited scale in Sylhet, Cox's Bazar and Chittagong Hill Tracts. Common bean is planted in Bangladesh during post-monsoon when soil moisture declines as a result the crop encounters drought particularly at its reproductive phase. Among the grain legumes, common bean is relatively sensitive to drought [2]. Water stress during reproductive development of a crop is usually associated with a large decrease in yield. Even short diurnal fluctuations in the plant water status at anthesis can adversely affect the development of reproductive organs [3]. Therefore, it is important to gain a better understanding of the influence of water stress on the plant water status and its relationship with reproductive responses in common bean genotypes. This may help understand the mechanism of water stress tolerance in common bean. This knowledge of water stress tolerance in common bean may accelerate its breeding process by using physiological or molecular indicators. The objective of this study was to understand the effect of water stress on the leaf water status and its relationship with the reproductive responses of relatively tolerant and susceptible common bean genotypes.

\section{Materials and Methods}

Two relatively tolerant (BB24 and BB43) and two relatively susceptible (BARI busbean-2 and BB04) common bean genotypes, selected from the previous experiment, were used in this study. Seeds were sown in plastic pots of $24 \mathrm{~cm}$ in diameter and $30 \mathrm{~cm}$ in height. The pots were filled with a mixture of soil and cowdung at a ratio of 4:1. A pot contained $14 \mathrm{~kg}$ of soil which was equivalent to $10.9 \mathrm{~kg}$ of oven dry soil at $27.5 \%$ of field capacity (FC) moisture. Soil used in the pot was sandy loam. The soil in a pot was fertilized uniformly with 0.9, 0.8 and $0.8 \mathrm{~g}$ of urea, triple super phosphate and muriate of potash, respectively corresponding to 160,150 and $150 \mathrm{~kg}$ of urea, triple super phosphate and muriate of potash per hectare, respectively. Fifty per cent of the amount of urea, and $100 \%$ of triple super phosphate and muriate of potash were mixed with soil before the sowing of seeds. The rest amount of urea was top-dressed at 30 days after sowing. Though common bean is a legume crop no effective nodules were found in the root because of absence of suitable strains of Rhizobia in Bangladesh soil, hence high dose of $\mathrm{N}$ fertilizer was used. After seedling establishment, two uniform and healthy seedlings were allowed to grow in a pot. Two sets of plants namely water stressed (50\% of FC) and non-stressed (80\% of FC) plants were grown. Water stress was imposed at 12 days after seedling emergence and maintained throughout the growing season. The pots were weighed at one-day intervals and the water lost by evapo-transpiration was compensated by adding requisite amount of water to the pot. All sorts of agronomic practices were done for both the sets of plants. The experiment was laid out in completely randomized (factorial) design with four replications. Two plants per pot were considered as one replication. There were eight treatment combinations including four genotypes and two watering treatments i.e. non stress and water stress treatments. The experiment was conducted in a net house covered with polyethylene sheet in the agronomy farm at the Bangabandhu Sheikh Mujibur Rahman Agricultural University, Salna, Gazipur, Bangladesh.

\subsection{Whole Plant Transpiration Rate}

The whole pant transpiration rate was measured at the pod development stage in between 12:00 noon and 13:00 hours. The pot was weighed once at a given time and again one hour later in the day time. The rate of whole plant transpiration was estimated by calculating the difference in pot weight in one hour. Total leaf area was measured at the same time. The transpiration rate was expressed in $\mathrm{mg}_{2} \mathrm{Odm}^{-2} \cdot \mathrm{h}^{-1}$. 


\subsection{Leaf Water Status}

Leaf water status was monitored at 4-leaf and pod development stages. Two youngest fully expanded leaves from two plants in each pot were selected for leaf water measurement i.e. two leaves per pot were considered as one replication. Measurements were done diurnally at 06:30 (pre-dawn), 10:30 (morning), 13:30 (noon) and 17:00 (evening) hours. Leaf water potential (LWP) and relative water content (RWC) were measured. The LWP was measured by using pressure chamber method [4] and RWC was calculated by using the following equation [5] [6]:

$$
\mathrm{RWC}(\%)=(\mathrm{FW}-\mathrm{DW}) /(\mathrm{TW}-\mathrm{DW}) \times 100
$$

where, FW, DW and TW were the fresh-, oven-dry- and turgid weight of the leaf discs, respectively. A sharp puncher was used to take eight leaf discs each of $10 \mathrm{~mm}$ in diameter avoiding the midrib and major veins in the leaf. Turgid weight was determined after the leaf discs had been kept in distilled water for more than four hours in darkness. Thereafter the leaf discs were dried in an oven at $65^{\circ} \mathrm{C}$ for eight hours and their dry weight was taken. The midday drop in RWC was calculated as a ratio of RWC at midday (13:30 h) to that at the pre-dawn (06:30 h).

\subsection{Reproductive Responses}

At flowering, four plants from each genotype were selected and their flowers that opened each day under non-stress and water stress conditions were counted and tagged with different color-coated wire each day. Counting and tagging of flowers continued till maturity. Pod setting percentage was calculated as the ratio of pod set at harvest to the total number of flowers borne expressed in percentage.

\section{Results and Discussion}

\subsection{Whole Plant Transpiration Rate}

The whole plant transpiration rate in all the four common bean genotypes decreased under water stress condition. The genotypes BB04 and BARI bushbean-2 showed higher transpiration rate than the genotypes BB24 and BB43 (Table 1). The reduction in transpiration rate was higher in BB24 and BB43 while that was the least in the genotype BB04 followed by BARI bushbean-2. Whole plant transpiration rate was 35\% lower in BB24, while that was 26\% lower in BB43 than the genotype BB04. This indicates that the genotypes BB24 and BB43 conserved more water than BB04. The decrease in transpiration rate under stress conditions may be considered as a drought avoidance mechanism in common bean [7].

Table 1. Whole plant transpiration rate in common bean genotypes at pod development stage under non stress and water stress conditions.

\begin{tabular}{|c|c|c|c|}
\hline \multirow{2}{*}{ Genotypes } & \multicolumn{3}{|c|}{ Whole plant transpiration rate $\left(\mathrm{mgH}_{2} \mathrm{O} / \mathrm{dm}^{2} / \mathrm{h}\right)$} \\
\hline & Non stress & Water stress & Difference \\
\hline BB43 & 80.52 a & $39.89 \mathrm{~d}$ & $* *$ \\
\hline BB24 & $76.26 \mathrm{~b}$ & 34.62 e & $* *$ \\
\hline BARI bushbean-2 & $73.14 \mathrm{~b}$ & $50.28 \mathrm{c}$ & $* *$ \\
\hline \multirow[t]{2}{*}{ BB04 } & $74.67 \mathrm{~b}$ & $53.04 \mathrm{c}$ & $* *$ \\
\hline & ance of F-tes & & \\
\hline Genotype (G) & \multicolumn{2}{|c|}{$* *$} & \\
\hline Water stress (S) & \multicolumn{2}{|c|}{$* *$} & \\
\hline Interaction $(\mathrm{G} \times \mathrm{S})$ & \multicolumn{2}{|c|}{$* *$} & \\
\hline
\end{tabular}

** indicates $1 \%$ level of probability. Mean followed by the same letter represent not significantly different by the DMRT at 5\% level. 


\subsection{Effect of Water Stress and Genotypes on Leaf Water Potential (LWP)}

Dawn to dusk variation in LWP followed a classical elliptical curve (Figure 1) both at 4-leaf and pod development stages. Diurnal variation in LWP was not measured in this experiment; however, a classical bell-shaped curve of LWP in maize and sorghum [8]. From the figures it is evident that a minimum LWP around noon prevailed in all the genotypes. Diurnal variations in LWP in response to diurnal changes in evaporative demand have been documented for diverse plant species in the field [9].

Initially, LWP in the four genotypes differed at both the growth stages (Table 2 and Table 3). There was no significant interaction of genotype and water stress in daily variation in LWP at both the stages except at noon. Under non stress condition, the variations in LWP were more or less similar in BB24 and BB43, but lower in BB04 and BARI bushbean-2. The LWP declined more at noon and recovered slightly in the evening in all the
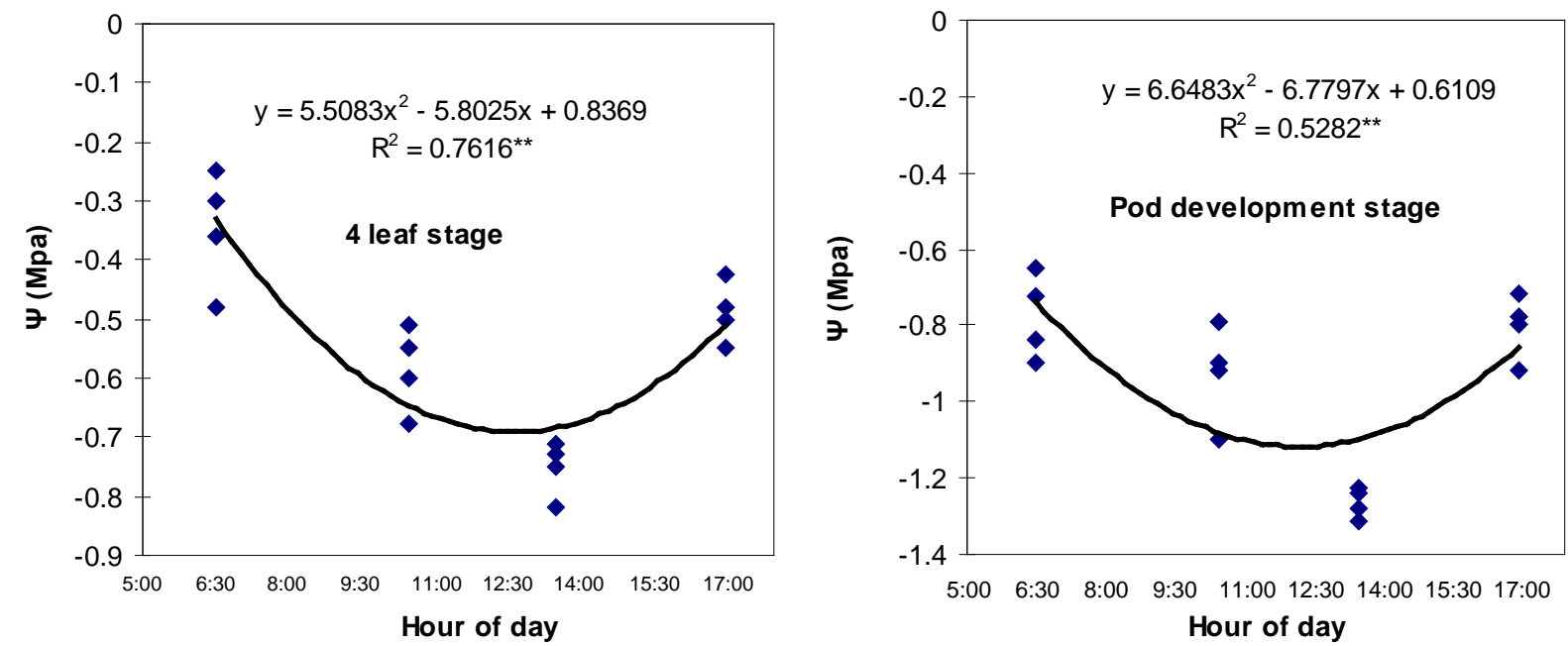

Figure 1. Diurnal pattern of LWP ( $\Psi)$ in third uppermost expanding leaves of water stressed common bean genotypes at 4-leaf and pod development stages.

Table 2. Diurnal variation in LWP and RWC of common bean genotypes under two moisture regimes at 4-leaf stage.

\begin{tabular}{|c|c|c|c|c|c|c|c|c|c|}
\hline \multirow{2}{*}{ Moisture level } & \multirow{2}{*}{ Genotypes } & \multicolumn{4}{|c|}{ LWP (MPa) } & \multicolumn{4}{|c|}{ RWC (\%) } \\
\hline & & $06: 30 \mathrm{~h}$ & $10: 30 \mathrm{~h}$ & $13: 30 \mathrm{~h}$ & $17: 00 \mathrm{~h}$ & $06: 30 \mathrm{~h}$ & $10: 30 \mathrm{~h}$ & $13: 30 \mathrm{~h}$ & $17: 00 \mathrm{~h}$ \\
\hline \multirow{4}{*}{ Non stress } & BB43 & -0.210 & -0.470 & $-0.600 \mathrm{a}$ & -0.380 & 89.71 & 85.12 & 83.64 & 84.68 \\
\hline & BB24 & -0.175 & -0.450 & $-0.583 a$ & -0.350 & 90.32 & 86.34 & 85.60 & 86.45 \\
\hline & BARI bushbean-2 & -0.250 & -0.510 & $-0.650 \mathrm{ab}$ & -0.425 & 88.14 & 82.76 & 81.34 & 79.24 \\
\hline & BB04 & -0.400 & -0.540 & $-0.650 \mathrm{ab}$ & -0.430 & 88.80 & 81.42 & 80.82 & 83.46 \\
\hline \multirow{4}{*}{ Water stress } & BB43 & -0.300 & -0.510 & $-0.710 \mathrm{bc}$ & -0.425 & 85.6 & 81.87 & 79.12 & 82.51 \\
\hline & BB24 & -0.250 & -0.550 & $-0.817 \mathrm{~d}$ & -0.480 & 86.51 & 82.16 & 80.19 & 83.22 \\
\hline & BARI bushbean-2 & -0.360 & -0.600 & $-0.750 \mathrm{~cd}$ & -0.500 & 83.26 & 79.43 & 75.68 & 81.31 \\
\hline & BB04 & -0.480 & -0.675 & $-0.730 \mathrm{bc}$ & -0.550 & 83.47 & 77.61 & 72.14 & 75.17 \\
\hline \multicolumn{10}{|c|}{ Significance of F-test } \\
\hline \multicolumn{2}{|c|}{ Genotype (G) } & $* *$ & $* *$ & NS & $* *$ & NS & $*$ & $* *$ & $* *$ \\
\hline \multicolumn{2}{|c|}{ Water stress (S) } & $* *$ & $* *$ & $* *$ & $* *$ & $* *$ & $* *$ & $* *$ & $* *$ \\
\hline \multicolumn{2}{|c|}{$\mathrm{G} \times \mathrm{S}$} & NS & NS & * & NS & NS & NS & NS & NS \\
\hline
\end{tabular}

*, ** and NS, significant at $5 \%$ levels of probability. Mean followed by the same letter represent not significantly different by the DMRT at 5\% level. 
Table 3. Diurnal variation in LWP and RWC of common bean genotypes under two moisture regimes at pod development stage.

\begin{tabular}{|c|c|c|c|c|c|c|c|c|c|}
\hline \multirow{2}{*}{ Moisture level } & \multirow{2}{*}{ Genotypes } & \multicolumn{4}{|c|}{ LWP (MPa) } & \multicolumn{4}{|c|}{ RWC (\%) } \\
\hline & & $06: 30 \mathrm{~h}$ & $10: 30 \mathrm{~h}$ & $13: 30 \mathrm{~h}$ & $17: 00 \mathrm{~h}$ & $06: 30 \mathrm{~h}$ & $10: 30 \mathrm{~h}$ & $13: 30 \mathrm{~h}$ & $17: 00 \mathrm{~h}$ \\
\hline \multirow{4}{*}{ Non stress } & BB043 & -0.540 & -0.725 & $-0.860 \mathrm{a}$ & -0.630 & 83.42 & 79.40 & 75.84 & 78.17 \\
\hline & BB024 & -0.530 & -0.700 & $-0.810 \mathrm{a}$ & -0.610 & 85.20 & 81.76 & 77.20 & 80.05 \\
\hline & BARI bushbean-2 & -0.650 & -0.900 & $-1.020 \mathrm{~b}$ & -0.680 & 80.47 & 77.41 & 71.44 & 73.62 \\
\hline & BB04 & -0.690 & -1.025 & $-1.050 \mathrm{~b}$ & -0.710 & 79.51 & 76.26 & 69.89 & 71.19 \\
\hline \multirow{4}{*}{ Water stress } & BB043 & -0.725 & -0.790 & $-1.225 \mathrm{c}$ & -0.780 & 77.19 & 72.90 & 69.63 & 73.36 \\
\hline & BB024 & -0.650 & -0.900 & $-1.310 \mathrm{c}$ & -0.720 & 78.50 & 74.46 & 70.68 & 75.48 \\
\hline & BARI bushbean-2 & -0.840 & -0.920 & $-1.240 \mathrm{c}$ & -0.800 & 73.67 & 68.21 & 62.38 & 70.12 \\
\hline & BB04 & -0.900 & -1.100 & $-1.280 \mathrm{c}$ & -0.920 & 71.14 & 66.14 & 58.46 & 65.64 \\
\hline \multicolumn{10}{|c|}{ Significance of F-test } \\
\hline \multicolumn{2}{|c|}{ Genotype (G) } & $* *$ & $* *$ & $*$ & $* *$ & $* *$ & $*$ & $* *$ & $* *$ \\
\hline \multicolumn{2}{|c|}{ Water stress (S) } & $* *$ & $*$ & $* *$ & $* *$ & $* *$ & $* *$ & $* *$ & $* *$ \\
\hline \multicolumn{2}{|c|}{$G \times S$} & NS & NS & $*$ & NS & NS & NS & NS & NS \\
\hline
\end{tabular}

*,** and NS, significant at 5\% levels of probability. Mean followed by the same letter represent not significantly different by the DMRT at 5\% level.

genotypes. At noon, the LWP was the lowest $(-0.65$ and $-1.05 \mathrm{MPa})$ in BB04 and the highest $(-0.583$ and $-0.81 \mathrm{MPa}$ ) in BB24 at 4-leaf and pod development stages, respectively under non stress condition. Under water stress condition, the LWP was always lower than under non stress condition. The genotype BB04 exhibited more negative LWP followed by BARI bushbean- 2 in the all time of a day except at midday. At midday, the genotype BB24 exhibited lower LWP ( -0.817 and $-1.31 \mathrm{MPa})$ than BB04 ( -0.73 and $-1.28 \mathrm{MPa})$ at both the stages, respectively. At pod development stage, BARI bushbean-2 showed slightly lower LWP (-1.24 MPa) than BB43 (-1.225 MPa) during midday.

\subsection{Effect of Water Stress and Genotypes on Relative Water Content (RWC)}

Water stress significantly reduced RWC in all the time of a day (Table 2 and Table 3). The interaction of genotype and water stress was not significant. In all the occasions, the RWC was higher in plants of BB24 and BB43 than in plants of BB04 and BARI bushbean-2 both under non stress and water stress conditions. Differences in RWC might have arisen from differences in osmotic adjustment. Under water stress condition, the midday drop of RWC was minimal (7.31\% and 9.96\%) in BB24 and (7.57\% and 9.79\%) in BB43 but it was maximal (13.57\% and $17.82 \%)$ in BB04 followed by (9.10\% and 15.32\%) in BARI bushbean-2 at 4-leaf and pod development stage, respectively (Table 4).

\subsection{Relationship between Relative Water Content and Leaf Water Potential}

Relative water content (RWC) and leaf water potential (LWP) were significantly associated across the treatments in the four genotypes (Figure 2 and Figure 3). The relationships were significant for all the genotypes. However, the relationship was stronger in BB24 followed by BB43 and BB04. There was moderate relationship in BARI bushbean-2 $\left(\mathrm{R}^{2}=0.609\right)$ at pod development stage.

The genotype BB24 showed a smaller decrease in RWC with a large decrease in LWP only at midday; while, a larger decrease in RWC with a lower LWP in all the time of a day except at midday was noticed in BB04 (Table 2 and Table 3). The slopes of the linear regressions were lower in BB24 and BB43 than in BB04 and BARI bushbean-2. However, the differences in the slopes were significant only between BB24 and BB04 (P < $0.05)$ at both the growth stages. This means that the rate of decrease in RWC due to a decremented change in LWP was significantly faster in the genotype BB04 than in BB24. Therefore, the genotype BB24 was able to 
Table 4. Midday drop of RWC in common bean genotypes under two moisture regimes at two growth stages.

\begin{tabular}{ccc}
\hline & \multicolumn{2}{c}{ Midday drop of RWC (\%) } \\
\cline { 2 - 3 } Genotypes & Non stress & Water stress \\
\cline { 2 - 3 } BB43 & At 4-leaf stage & 7.57 \\
BB24 & 6.77 & 7.31 \\
BARI bushbean-2 & 5.23 & 9.10 \\
BB04 & 7.71 & 13.57 \\
& 8.98 & 9.79 \\
BB43 & At pod development stage & 9.96 \\
BB24 & 9.08 & 15.32 \\
BARI bushbean-2 & 9.40 & 17.82 \\
BB04 & 11.22 & 12.09 \\
\hline
\end{tabular}

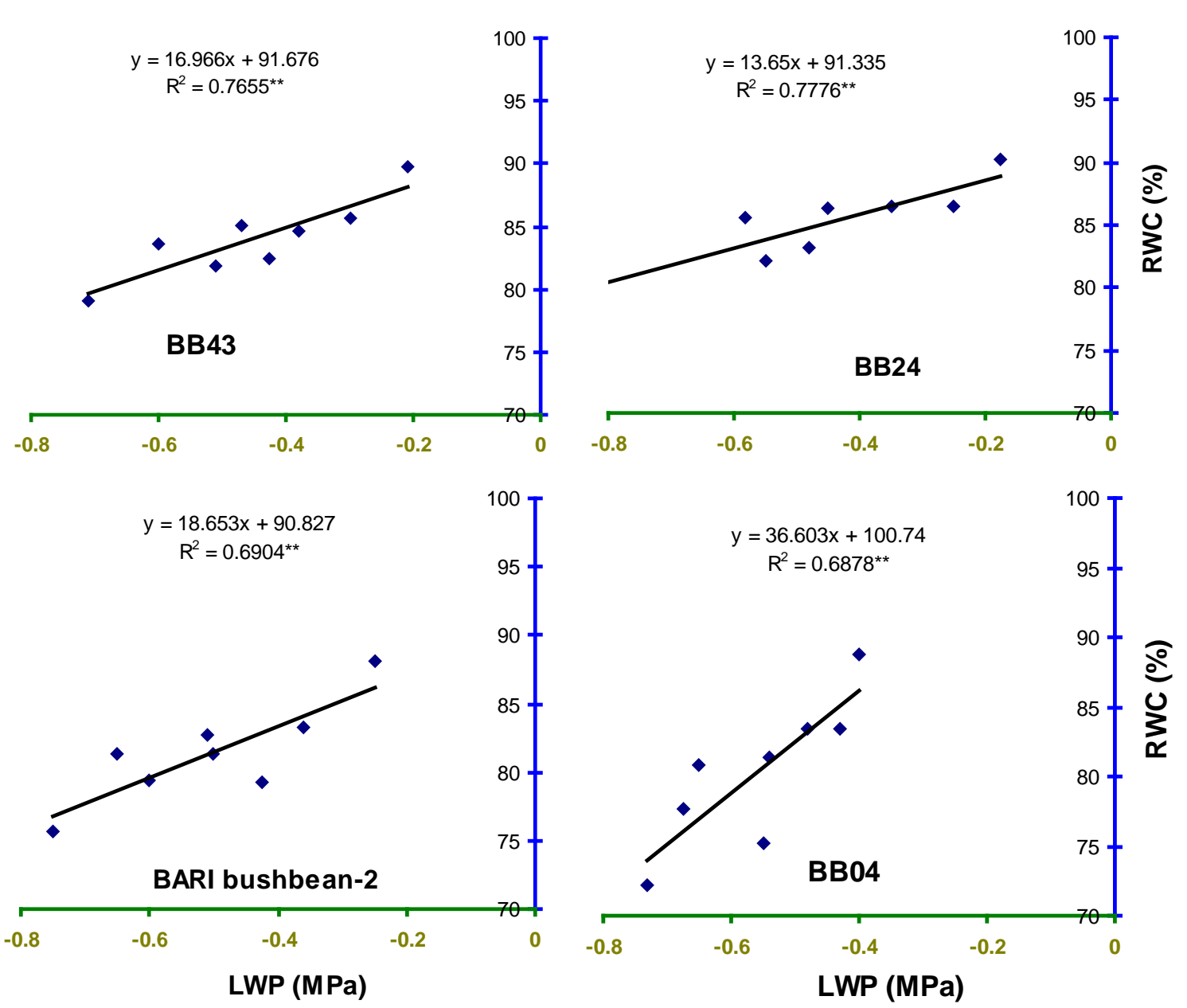

Figure 2. Relationship between RWC and LWP in common bean genotypes under non stress and water stress conditions at 4 -leaf stage. $* *$ indicates significance at $1 \%$ level. 


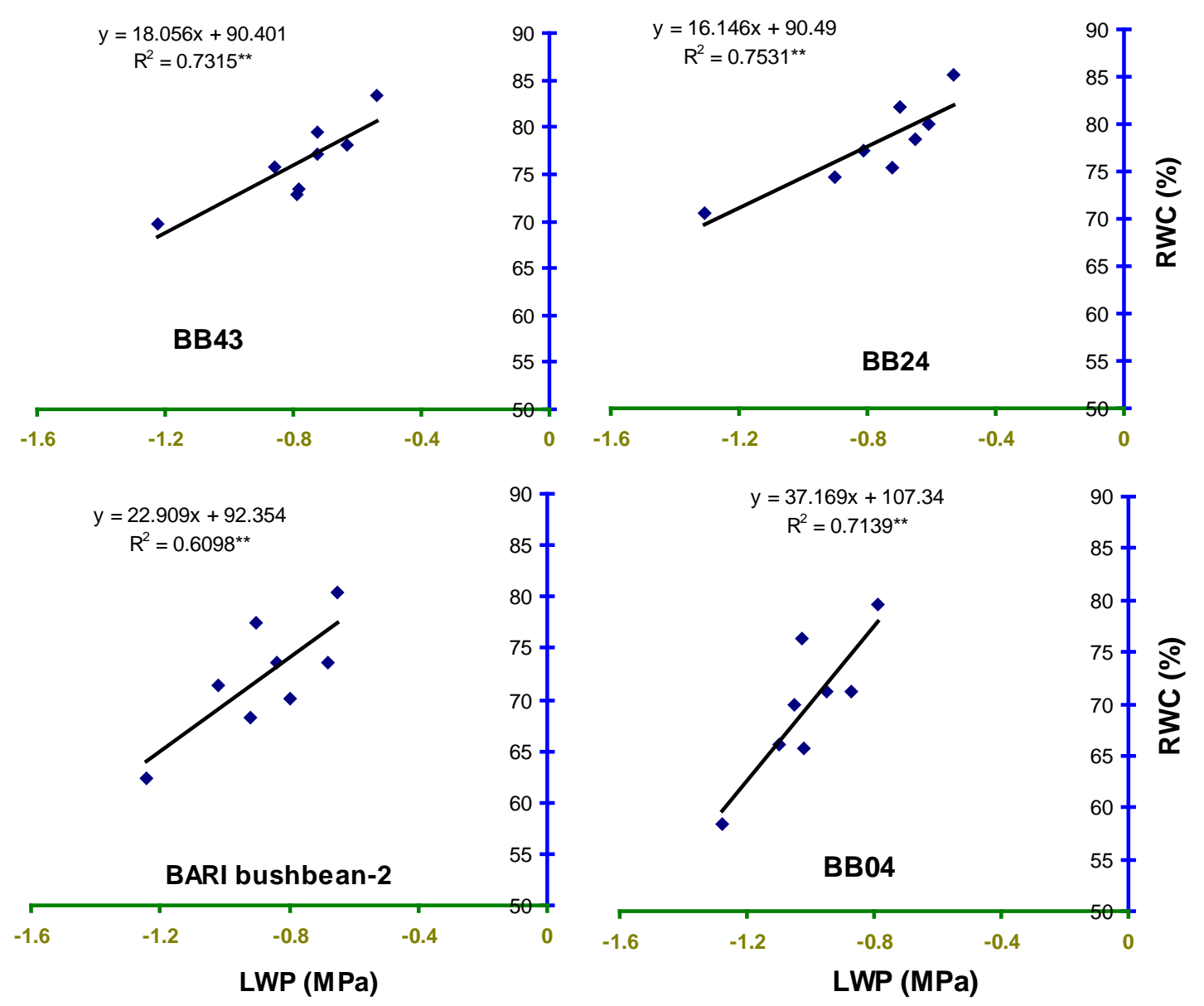

Figure 3. Relationship between RWC and LWP in common bean genotypes under non stress and water stress conditions at pod development stage. ** indicate significance at $1 \%$ level.

develop a LWP gradient from soil to plant, and displayed a higher ability to extract moisture at low soil water content. This mechanism may contribute to the maintenance of a higher RWC with decreasing LWP. Similar findings have been reported from elsewhere of the world in common bean [10]-[14]. Maintenance of higher RWC with decreasing LWP might contribute to stress tolerance in Haibushi compared to susceptible cultivar Kentucky Wonder of Phaseolus vulgaris probably due to maintenance of osmoregulation [11] [12].

\subsection{Reproductive Responses}

Pod setting ratio was the highest in BB24 followed by BB43, BARI bushbean-2 and BB04 in descending order both in non-stress and water stress conditions (Figure 4). Water stress reduced the pod setting ratio.

\subsection{Association of Leaf Water Status and Reproductive Responses}

Significant relationships were observed between RWC (midday), midday drop of RWC and the pod setting ratio (Figure 5). However, midday drop of RWC (Figure 5(b)) showed a stronger correlation with the pod setting ratio than midday RWC (Figure 5(a)). Leaf water potential had insignificant relationship with the pod setting ratio (Figure 5(c)). However, the LWP was not related with pod setting ratio in Phaseolus vulgaris [11]. Genotypes with a smaller reduction in midday drop of RWC set more pods and vice versa. The midday drop was found less in BB04 and BARI bushbean-2, this might be the reason for higher pod set in non stress condition. The reduction in midday drop was, however, pronounced under water stress conditions, which might be due to the lower maintenance of RWC with declining LWP. The midday drop of RWC adversely affected the photosynthetic rates and consequently resulted in low siliqua set in Brassica species [5]. A heat sensitive cultivar Kentucky 


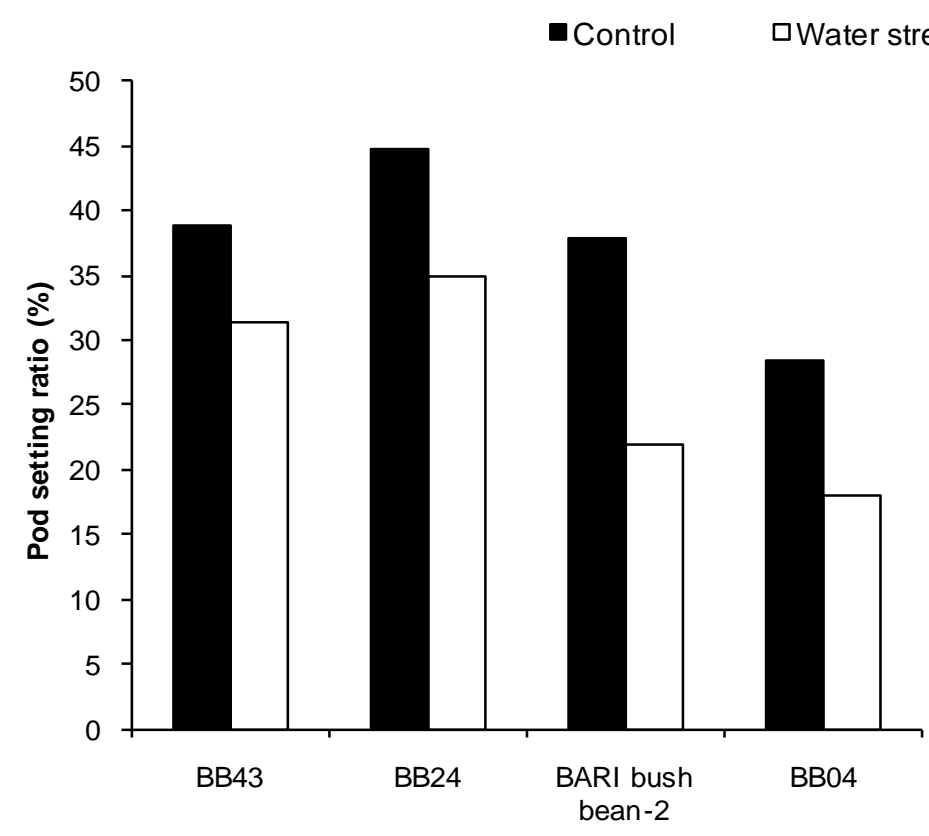

\section{Genotype}

Figure 4. Pod setting ratio in common bean genotypes in non-stressed (closed histogram) and water stressed (open histogram) plants.

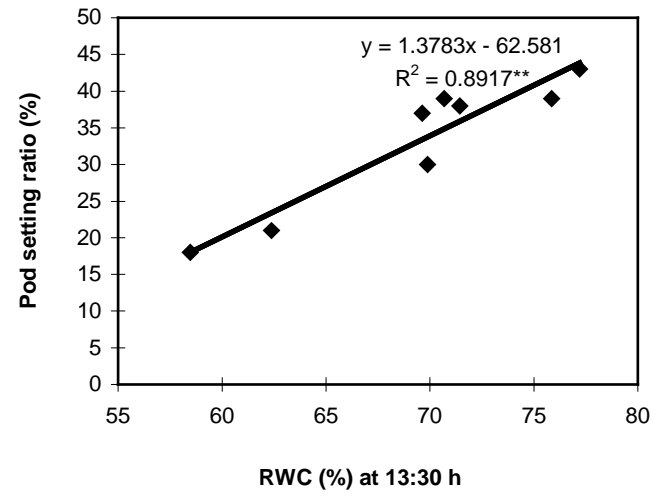

(a)

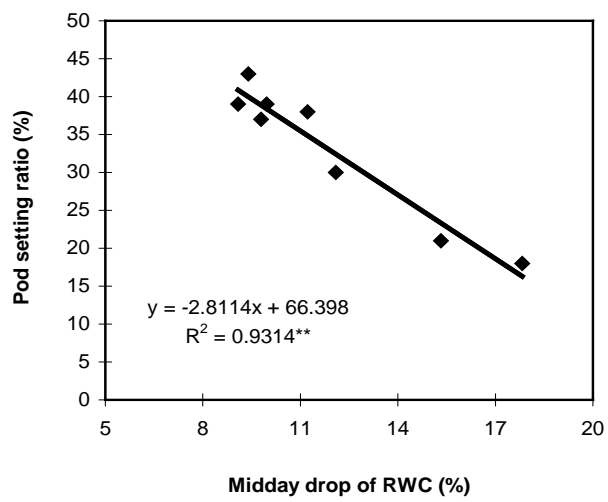

(b)

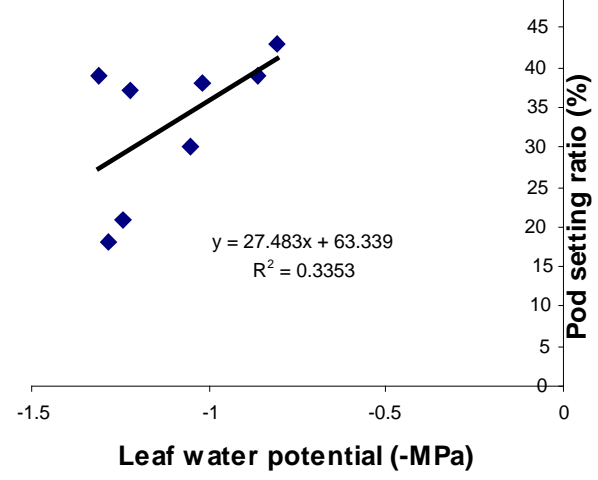

(c)

Figure 5. Relationship between pod setting ratio and RWC at 13:30 h (a), midday drop of RWC (b) and LWP (c). Data from both non-stressed and stressed plants at pod development stage were used for establishing the relationships. ** indicates significantly different at $1 \%$ level. 
Wonder of Phaseolus vulgaris showed a similar reduction in LWP and pod setting ratio [3]. In the present study, the LWP was not significantly related with the pod setting ratio, though such a relationship was observed in wheat [15].

The results of this study revealed the existence of a substantial variation in the water status in different genotypes of common bean. The genotypes namely BB24 and BB43 maintained high RWC with declining LWP and set a large number of pods. On the contrary, the genotypes namely BB04 and BARI bushbean-2 failed to maintain high RWC with declining LWP, and consequently set the minimal number of pods. Osmotic adjustment and cell wall elasticity enable the plants to maintain a high RWC, turgor and other turgor-related processes during water deficit condition [5]. This allows the tolerant plants to survive longer than the sensitive ones under stress conditions. The genotype BB04 and BARI bushbean-2 showed a large reduction in the pod setting ratio due to water stress. This reduction in pod setting ratio in common bean may be attributed to the low LWP at pre-dawn and in the evening. It has been reported that the common bean strains 45817, Ishigaki-2 and 3028520, and cultivars Kurodane Kinugasa and Haibushi maintained high RWC with declining LWP and set a large number of pods [11]. Midday RWC had strong positive association with the pod setting ratio.

\section{Conclusion}

The control of excessive transpiration during midday hours and the maintenance of a high RWC with decreasing LWP may have contributed to the stress tolerance in BB24. Therefore, selection of genotype with small midday drop of RWC or high midday RWC under slow developing water deficit conditions may be desirable in common bean under water stress conditions. However, further studies should be carried out to elucidate the mechanisms underlying plant water status of water stress tolerance in common bean.

\section{Acknowledgements}

Ph.D. Fellowship provided to A.K. Choudhury by Bangladesh Agricultural Research Institute is gratefully acknowledged.

\section{Conflict of Interests}

This study was conducted at Bangabandhu Sheikh Mujibur Rahman Agricultural University, Gazipur-1706, Bangladesh and $\mathrm{Ph} \mathrm{D}$ work of the first author.

\section{References}

[1] Graham, P.H. and Ranalli, P. (1997) Common Bean (Phaseolus vulgaris L). Field Crops Research, 53, 131-146. http://dx.doi.org/10.1016/S0378-4290(97)00112-3

[2] Haterlein, A.J. (1983) Bean. In: Tearce, I.D. and Peet, M.M., Eds., Crop-Water Relations, Wiley Publication, New York, 157-185.

[3] Tsukaguchi, T., Kawamitsu, Y., Taheda, H., Suzuki, K. and Egawa, Y. (2003) Water Status of Flower Buds and Leaves as Affected by High Temperature in Heat-Tolerant and Heat-Sensitive Cultivars of Snap Bean (Phaseolus vulgaris L.). Plant Production Science, 6, 24-27. http://dx.doi.org/10.1626/pps.6.24

[4] Scholander, P.F., Hammel, H.T., Bradstreet, E.D. and Hemmingsen, E.A. (1965) Sap Pressure in Vascular Plants. Science, 148, 339-346. http://dx.doi.org/10.1126/science.148.3668.339

[5] Kumar, A., Singh, P., Singh, D.P., Singh, H. and Sharma, H.C. (1984) Differences in Osmoregulation in Brassica Species. Annals of Botany, 54, 537-541.

[6] Weatherley, P.E. (1962) A Re-Examination of the Relative Turgidity Technique for Estimating Water Deficits in Leaves. Australian Journal of Biological Science, 15, 413-428.

[7] Islam, M.S., Haque, M.M., Khan, M.M., Hidaka, T. and Karim, M.A. (2004) Effect of Fertilizer Potassium on Growth, Yield and Water Relations of Bushbean (Phaseolus vulgaris L). under Water Stress Conditions. Japanese Journal Tropical Agriculture, 48, 1-9.

[8] Acevedo, E., Fereres, E., Hsiao, T.C. and Henderson, D.W. (1979) Diurnal Growth Trends, Water Potential, and Osmotic Adjustment of Maize and Sorghum Leaves in the Field. Plant Physiology, 64, 476-480. http://dx.doi.org/10.1104/pp.64.3.476

[9] Reicosky, D.C., Campbell, R.B. and Doty, C.W. (1975) Diurnal Fluctuation of Leaf-Water Potential of Corn as Influ- 
enced by Soil Matric Potential and Microclimate. Agronomy Journal, 67, 380-385. http://dx.doi.org/10.2134/agronj1975.00021962006700030025x

[10] Coyne, P.I., Bradford, A. and Dewald, C.I. (1982) Leaf Water Relations and Gas Exchange in Relation to Forage Production in Four Asiatic Blue Stems. Crop Science, 22, 1036-1040. http://dx.doi.org/10.2135/cropsci1982.0011183X002200050034x

[11] Omae, H., Kumar, A., Egawa, Y., Kashiwaba, K. and Shono, M. (2005) Genotypic Differences in Plant Water Status and Relationship with Reproductive Responses in Snap Bean (Phaseolus vulgaris L.) during Water Stress. Japanese Journal Tropical Agriculture, 49, 1-7.

[12] Kumar, A., Omae, H., Egawa, Y., Kashiwaba, K. and Shono, M. (2005) Influence of Water and High Temperature Stresses on Leaf Water Status of (Phaseolus vulgaris L.). Japanese Journal Tropical Agriculture, 49, 109-118.

[13] Stoyanov, Z.Z. (2005) Effects of Water Stress on Leaf Water Relations of Young Bean Plants. Journal of Central European Agriculture, 6, 5-14.

[14] Rodrigues, M.I., Chaves, M.M., Wendler, R., David, M.M., Quick, W.P., Leegood, R.C., Stitt, M. and Pereira, J.S. (1993) Osmotic Adjustment in Water Stressed Grapevine Leaves in Relation to Carbon Assimilation. Australian Journal of Plant Physiology, 20, 309-321. http://dx.doi.org/10.1071/PP9930309

[15] Saini, H.S., Sedgley, M. and Aspinall, D. (1984) Developmental Anatomy in Wheat of Mail Sterility Induced by Heat Stress, Water Deficit or Abscisic Acid. Australian Journal of Plant Physiology, 11, 243-253. http://dx.doi.org/10.1071/PP9840243 